Horizons philosophiques

\title{
Analyse d'un corpus iconographique rassemblé par Maxime Préaud ou Aristote et la mélancolie
}

\section{Chantal Fleury}

Volume 1, numéro 1, automne 1990

Sémiotiques $1:$ mises au point, mises en question

URI : https://id.erudit.org/iderudit/800863ar

DOI : https://doi.org/10.7202/800863ar

Aller au sommaire du numéro

Éditeur(s)

Collège Édouard-Montpetit

ISSN

1181-9227 (imprimé)

1920-2954 (numérique)

Découvrir la revue

\section{Citer cet article}

Fleury, C. (1990). Analyse d'un corpus iconographique rassemblé par Maxime Préaud ou Aristote et la mélancolie. Horizons philosophiques, 1(1), 101-109.

https://doi.org/10.7202/800863ar d'utilisation que vous pouvez consulter en ligne. 


\section{Analyse d'un corpus iconographique rassemblé par Maxime Préaud \\ ou}

Aristote et la mélancolie

Le problème $X X X$ d'Aristote, réintitulé L'Homme de génie et de mélancolie par J. Pigeaud, est un traité sur la causalité qu'entretiennent forme et matière. II nous explique comment notre nature propre est liée à la proportion définie des éléments qui nous constituent et ce par quoi l'on est un être de mélancolie. Afin de mieux comprendre le mélancolique, nous nous appuierons sur le corpus iconographique rassemblé par Maxime Préaud dans son livre Mélancolies de même que sur les écrits d'Aristote.

Le livre Mélancolies de Maxime Préaud traite de la récurrence d'une forme : celle d'une personne assise la tête appuyée sur une main. Cette attitude de désintérêt apparent face au monde sensible semble de prime abord un geste de détachement. Or Aristote, dans son problème XXX traitant de la mélancolie, précise le contraire en démontrant que le mélancolique est un être fort sensible et réceptif dans sa nature. Nous tenterons de lever le sombre voile qui masque cet être doué de grande sensibilité, mais qui, par son attitude, semble ne pas participer à la réalité. Nous traiterons de la causalité de la forme mélancolique, étudiée et interprétée par Maxime Préaud selon 
un regard péripatéticien, en nous limitant au toucher, c'està-dire au sens primordial de notre sensibilité connaissante. En observant Dürer et les autres représentations mélancoliques recueillies par Préaud, on constate que ce toucher est figuré par une main vagabonde communiquant avec le monde sensible.

Le mélancolique a trois attitudes constantes relevées par Préaud. La première attitude est celle d'une personne assise s'appuyant la tête d'une main. La seconde attitude, c'est la tête et le corps effondrés entre les deux mains libres. Dans la dernière, les deux mains soutiennent la tête, empêchant ainsi tout mouvement manuel. Nous nous attarderons à la première forme, la plus courante, du mélancolique. Si l'on observe longuement le burin de Dürer intitulé "Melencolia l", on voit le silence, le temps, la mort : «... une atmosphère de rêve qui imprègne l'estampe envahit également celui qui la regarde. Rêve, songe, vision, illusion, cauchemar, tous ces mots, proches sans être synonymes, viennent naturellement à la bouche de ceux qui entrent dans les images de mélancolie" ". Bien sûr, il y a cette main qui sert d'appui à cette tête trop lourde de pensées et une autre, libre de tout mouvement. Cette main, à travers le corpus iconographique est, la plupart du temps, en train de toucher, ou de vouloir atteindre, tenir ou manipuler quelque chose.

«Melencolia l» de Dürer montre un ange tenant un compas, un instrument qui mesure le monde sensible. Si ce n'est la main, c'est le regard qui touche ou embrasse les choses. "Le Mélancolique», d'après Jacob de Gheyn II, englobe à la fois tout ce que cet homme étreint de sa pensée, c'est-à-dire le monde. Un compas lui servant de mesure, il est conscient de son appartenance au monde sensible (assis sur la terre) et il doit pour saisir celui-ci, le mesurer. II suffit de parcourir la multitude d'images recueil- 


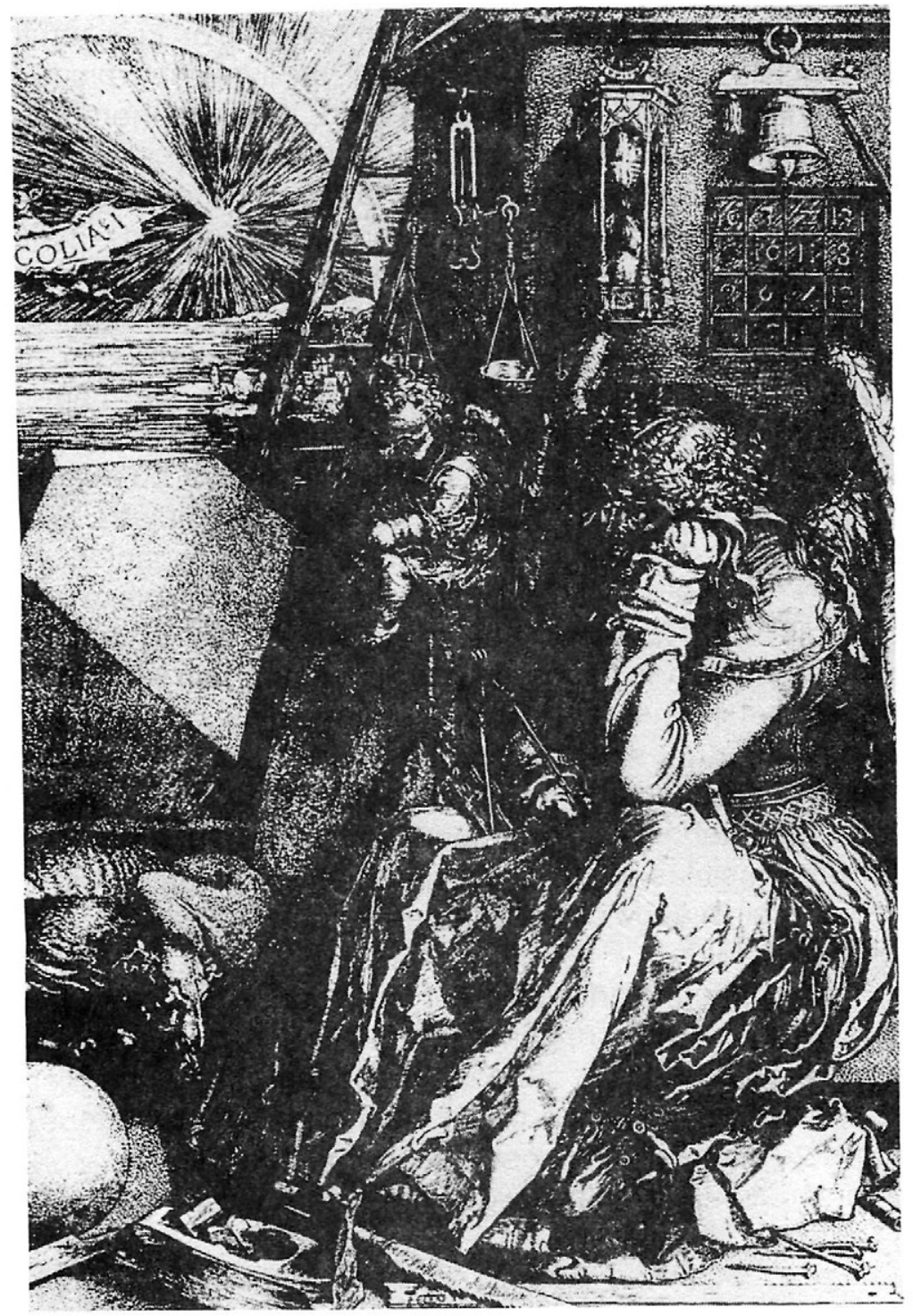

Albrecht Dürer : Melencolia I, burin, 1514.

Source : Maxime Préaud, Mélancolies, Paris, Herscher, 1982, p. 7. 
lies par Préaud symbolisant la mélancolie pour s'apercevoir que les mélancoliques ont un besoin rationnel ou irrationnel de toucher, d'atteindre. Que ce soit un livre, une plume, un animal, un bout de bois ou la mort, l'attitude même du mélancolique traduit son désir de participer au monde sensible tout en étant conscient de la limite de celui-ci. On peut inférer que le mélancolique connaît par les sens, mais surtout par le toucher, car son âme «reçoit les formes sensibles sans la matière, comme la cire prend [l'empreinte de] l'anneau sans le fer ni l'or, et reçoit le sceau d'or et d'airain mais non pas en tant qu'or ou airain. De même, la sensibilité relative à chaque sensible pâlit sous l'influence de ce qui possède la couleur, la saveur ou le son, non pas en tant que chacun de ces objets est dit [être telle chose], mais en tant qu'[il a] telle qualité et quant à sa forme ${ }^{2}$ ". La main libre du mélancolique devient alors le lien immédiat entre le sensible et les intelligibles car «il s'ensuit que l'âme est analogue à la main de même, en effet, que la main est un instrument d'instruments, ainsi l'intellect est forme des formes, et le sens, forme des sensibles. Mais puisqu'il n'y a, semble-t-il, aucune chose qui existe séparément en dehors des grandeurs sensibles, c'est dans les formes sensibles que les intelligibles existent, tant les abstractions ainsi appelées que toutes les qualités et affections des sensibles ${ }^{3}$."

L'homme mélancolique est donc habile de ses mains car il a un toucher supérieur à tous, "c'est l'organe de ce sens, et aucun autre, qui partage les individus entre bien et mal doués : ceux qui ont la chair dure sont mal doués intellectuellement, mais ceux qui ont la chair tendre, sont bien doués ${ }^{4}$. Le mélancolique a par son attitude naturelle

2. Aristote, De l'âme, Paris, J. Vrin, 1988, II, 12, 424 a 17.

3. Ibid., III, 8, 432 a 1.

4. Ibid., II, 9, 421 a 24. 


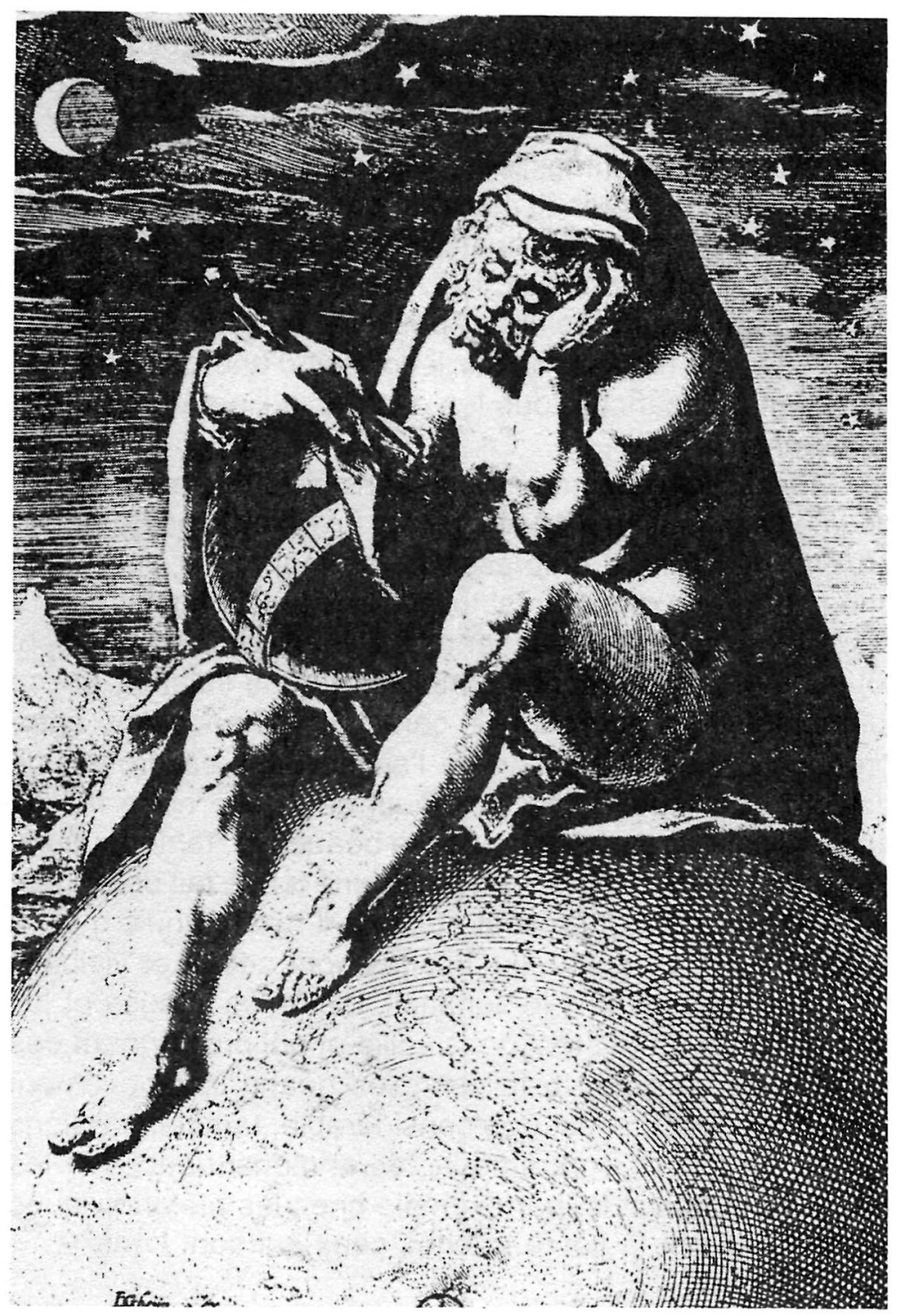

Jacob De Gheyn II (1565-1629) : Le Mélancolique, burin.

Source : Maxime Préaud, Mélancolies, Paris, Herscher, 1982, p. 22. 
(celle relevée dans le corpus d'images) toutes les prédispositions pour avoir la chair tendre. Le mélancolique connaît et communique par ce sens; c'est pourquoi il n'est pas étonnant que les mélancoliques soient savants, charpentiers, alchimistes, magiciens, philosophes, peintres, artistes, écrivains... puisqu'ils sont par nature doués pour observer, connaître et transformer le sensible, c'est-à-dire la Nature. Le mélancolique vit dans le creuset de l'expérience : car il est "celui qui possède au plus haut degré la science de l'universel, car il connaît d'une certaine manière [en puissance], tous les cas particuliers qui tombent sur l'universel ${ }^{5}$ ".

Prédisposé à une extrême sensibilité due au mélange de la bile noire, le mélancolique est un rêveur constamment en état de veille. Il embrasse de sa main libre un monde imaginaire et expérimental tout à la fois. L'imaginaire pour Aristote, c'est un mouvement en acte où l'intellect devient tous les objets du monde sensible et où le sujet se pense lui-même. C'est pourquoi "le caractère mélancolique entre presque dans la définition de l'artiste dans sa profession de foi ${ }^{\prime \prime}$. Le mouvement continuel de la bile noire fait de lui un visionnaire car "si on l'agite beaucoup, tantôt aucune image n'apparaît, tantôt il en paraît une tout à fait déformée, de sorte que l'objet se veut autre qu'il n'est, tandis que, si le liquide est en repos, les images sont nettes et visibles; de même aussi, dans le sommeil, tantôt les images et les mouvements qui restent de la veille et qui proviennent des sensations sont tout à fait annulés quand le mouvement dont il est question est trop considérable, tantôt les visions qui se produisent sont effrayantes et monstrueuses et les rêves sont malsains, par exemple chez les mélancoliques et ceux qui ont la fièvre et chez ceux qui sont ivres ${ }^{7}$ ".

5. Aristote, La Métaphysique, Paris, Vrin, 1986, 982 a 22.

6. Maxime Préaud, Mélancolies, op. cit., p. 13.

7. Aristote, Petit Traité d'histoire naturelle, (Budé), Paris, 1953, 461 a 15, 20. 
L'homme de mélancolie, par sa facilité de sentir les choses et par son inconstance, est un être déchiré entre désir et mesure : «mais, on le sait, les désirs naissent en lutte des uns contre les autres, et cela se produit quand raison et appétit militent en sens contraire : c'est le propre des êtres qui ont la perception du temps... ${ }^{8}$ " Le désir chez le mélancolique est grand car il est le résultat de ses visions. II sait que le monde sensible est tributaire de ses actions, de ses accidents et cherche par abstraction solitaire une échappatoire éphémère, mais il reste attaché par cette main vagabonde symbolisant ce qui constitue la vie. Son immortalité, il la vit à travers ses œuvres. Homme de désir, il est porté aux excès, exploitant ainsi tous ses sens afin d'obtenir ensuite un certain recul. Le toucher le ramène constamment à la vie, car le toucher est «le seul sens dont la privation entraîne la mort de l'animal ${ }^{9}$ ". Le toucher c'est ce que possède tout animal parce qu'il est nécessaire. "Quant aux autres sens, l'animal les possède comme nous l'avons dit, non pas en vue de l'être, mais en vue du bienêtre... ${ }^{10}$ ".

Le mélancolique a une conscience du monde hors du commun car il puise son inspiration dans le monde sensible. Les images de la mélancolie nous incitent à regarder au-delà des méditations solitaires qu'elles représentent. Ces images nous peignent un personnage complexe, fascinant, insaisissable. Homme de génie, le visionnaire exprime, à travers diverses réalisations, sa grande capacité de saisir le monde. II n'est pas l'homme du juste milieu, car il sait que ses désirs accomplis seront, en quelque sorte, sa mesure du monde (toujours le compas). La mélancolie conduit aux excès, ainsi voit-on génie et folie

8. Aristote, De l'âme, op. cit., III, 433 b 5.

9. Ibid., III, 435 b 4.

10. Ibid., III, 435 b 20. 
se côtoyer afin de nous livrer un être synonyme de sagesse. Le mélancolique est nécessaire, il n'est pas une nullité, un grand flanc-mou, relevant du domaine de la psychologie, car, dit Aristote, "tous les mélancoliques sont des êtres d'exceptions, et cela non par maladie, mais par nature ${ }^{11}$ ». Le mélancolique représente ce à quoi nous désirons tous accéder et que nous renions parce que la nature n'obéit qu'à elle-même et que la dualité de l'être n'est pas de tout repos. Le mélancolique est celui qui sait la mesure du désir.

\author{
Chantal Fleury \\ Université du Québec \\ à Trois-Rivières
}

11. Aristote, L'Homme de génie et de la mélancolie (Problème $X X X$ ), Paris, Petite bibliothèque Rivage, 1988, p. 107, 955 a 35, 40. 


\section{Références bibliographiques}

Aristote, De l'âme, J. Vrin, Paris, 1988.

Aristote, L'Homme de génie et de la mélancolie (Problème $X X X)$, Petite bibliothèque Rivage, Paris, 1988.

Aristote, La Métaphysique, Tome I, J. Vrin, Paris, 1986.

Aristote, Petit traité d'histoire naturelle, Éd. par R. Mugnier (Budé), Paris, 1953.

Préaud, Maxime, Mélancolies, Paris, Format/Art, Herscher, 1982.

Roussel, Fabrice, "Le concept de mélancolie chez Aristote", Revue d'histoire des sciences, XLI 3/4, juilletdécembre, 1988, p. 299 à 330. 